\author{
AMERICAN JOURNAL OF FOOD AND NUTRITION \\ Print: ISSN 2157-0167, Online: ISSN 2157-1317, doi:10.5251/ajfn.2012.2.1.21.25 \\ (C) 2012, ScienceHuß, http://www.scihub.org/AJFN
}

\title{
Body composition changes among lactating mothers In Abia State, Nigeria
}

\author{
Ukegbu, P.O. and Uwaegbute A.C. \\ Department of Human Nutrition and Dietetics, Michael Okpara University of Agriculture, \\ Umudike, PMB 7267, Abia State, Nigeria. \\ Corresponding author: Ukegbu Patricia Ogechi. +2348034289406, \\ ukegbu.patricia@mouau.edu.ng
}

\begin{abstract}
The study was carried out to evaluate body composition changes among nursing mothers in relation to their breastfeeding pattern. This prospective study was carried out at Federal Medical Centre, Umuahia, Abia State, Nigeria. A total of 213 mothers were recruited consecutively during BCG immunization of their babies aged 0-7 days. At recruitment, the mothers were classified into exclusive and nonexclusive breastfeeding (EBF and NEBF) groups. Maternal body weight, height, arm circumference and skinfold measurements were taken. Body fat ( $\mathrm{kg}$ and \%) and lean body mass (LBM) were calculated from predicted equations. These measurements were repeated during follow up visits at 6,14 and 24 weeks. Data analysis was performed using SPSS version 13. There was no significant difference in anthropometric and body composition parameters between mothers in the EBF and NEBF groups throughout the period ( $p>0.05$ ). Significant changes occurred in arm circumference, triceps, percentage of body fat and lean body mass among the EBF group over the period $(\mathrm{P}<0.05)$. The mothers in both groups were overweight $\left(\mathrm{BMl}>25 \mathrm{~kg} / \mathrm{m}^{2}\right)$ throughout the study period. Initial weight and body fat $(\mathrm{kg})$ loss occurred in both groups at 6 weeks, thereafter, there was progressive weight and body fat gain up to the $14^{\text {th }}$ week, after which a slight decline occurred. LBM loss was higher in EBF $(0.43 \mathrm{~kg} / \mathrm{month})$ compared to the NEBF group $(0.16 \mathrm{~kg} / \mathrm{month})$ over the study period. Irrespective of the breastfeeding pattern, this study revealed that there was no significant difference in body composition changes between EBF and NEBF mothers.
\end{abstract}

Keywords: Body composition, lactating mothers, breastfeeding pattern, Nigeria

\section{INTRODUCTION}

In Nigeria, the prevalence of exclusive breastfeeding was $17 \%$ in 2003 (NDHS, 2003), however this declined currently declined to $13 \%$ (NDHS, 2008). This decline was attributed to several factors. One of this was that mothers had the perception that exclusive breastfeeding was 'physically draining' on them (Nwankwo and Brieger, 2002; Naanyu, 2010). The energy cost of lactation is generally considered to represent a substantial drain on maternal nutritional metabolism (Lunn, 1996). The energy demand during lactation is usually met through various strategies which include increasing energy intake, mobilization of fat from maternal reserve developed during pregnancy and energy sparing through reduced physical activity (Sardurski et al.,
1988; Van Raaij et al., 1991; Vinoy et al., 2000; Lunn 2004). The available evidence about lactation shows that in malnourished mothers, the quality and quantity of breast milk is preserved at the expense of maternal health (Prentice et al., 1983). The high energy cost of lactation and the health and nutrition hazard that it could pose for the mother underline the need to monitor the nutritional status of lactating women in low-income populations for proper nutritional support.

Body composition refers to the constituents of the body namely lean body mass, fat mass and water. It is of great diagnostic value and a sensitive indicator of an individual's health and nutritional status. It is an indirect method based on prediction equations developed in a population in which the technique was 
validated against a reference method and is therefore population specific (Deurenberg, 1992). Information on changes in body composition between mothers practicing exclusive and nonexclusive breastfeeding for six months is scarce in Nigeria. Studies carried out in other parts of the world on the effect of lactation on postpartum body weight and fat are controversial. Some studies have not found any association (Dugdale and Eaton, 1989; Chou et al, 1999). Others have reported postpartum weight gain (Valleggia and Ellison, 2003), while some showed a significant loss in weight in lactating women during the postpartum period (Dewey et al., 1993; Barbosa et al., 1997; Vinoy et al., 2000). This has to be evaluated in the Nigerian context. This study therefore investigated changes in body composition of mothers practicing exclusive and nonexclusive breastfeeding.

\section{MATERIALS AND METHODS}

Subjects: The study was a prospective one carried out for a period of 24 weeks using 213 consecutively selected mothers who were attending BCG immunization clinic with their infants aged 0-7 days. Mothers were followed up at 6, 14 and 24 weeks. Inclusion criteria were lactating mothers who were healthy (defined as having no chronic illness), had given birth to full term infants weighting $\geq 2.5 \mathrm{~kg}$, had normal delivery and were willing to participate in the study. Informed and written consent were obtained from the subjects after the purpose of the study was explained to them. The ethics committee of the Federal Medical Centre, Umuahia, approved the study.

Methods: At recruitment, mothers were classified into exclusive (EBF) and non-exclusive breastfeeding (NEBF) group based on the feeding pattern of their infants. Baseline measurements were taken after delivery (0-7 days). Thereafter, anthropometry and breastfeeding pattern were monitored at 6, 14 and 24 weeks. Mothers who introduced any feeds/fluid at any particular point in time were assigned to the non exclusive breastfeeding group (NEBF).

\section{Anthropometric and body composition} measurements: The weight of the mothers was measured with a portable bathroom scale using standard methods (WHO, 1995) to the nearest $0.1 \mathrm{~kg}$. The women's height without shoes was measured using a portable stadiometer to the nearest $0.1 \mathrm{~cm}$ (WHO, 1995). Skinfold thickness was measured using skinfold caliper (Slimguide) at three body sites: biceps, triceps and suprailiac. Percent body fat and total body fat $(\mathrm{kg})$ were calculated using formulas of Durnin and Womersley (1974) shown to be valid for lactating women (Butte et al., 1985). Lean body mass (LBM) was calculated as body weight minus total body fat $(\mathrm{kg})$.

\section{STATISTICAL ANALYSIS}

Descriptive statistics such as percentages and means (SD) were used for data analysis. Baseline characteristics of the EBF and NEBF groups were compared with the use of student's t-test. Changes in anthropometry and body composition over time were analyzed using repeated ANOVA. A P-value of $\leq 0.05$ was regarded as statistically significant. Data was analyzed using SPSS software version 13 (SPSS, Chicago).

\section{RESULTS}

Breastfeeding pattern of lactating mothers practicing EBF and NEBF

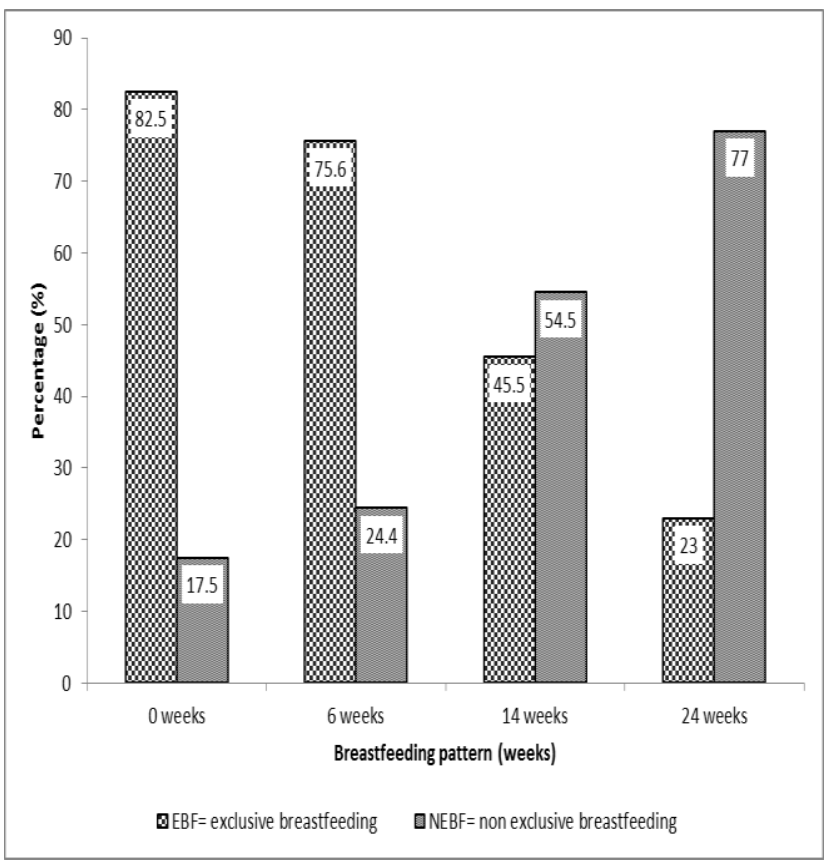

Fig.1 Breastfeeding pattern of lactating mothers practicing EBF and NEBF

A total of 213 women were enrolled in the study. The percentage of mothers practicing exclusive and non exclusive breastfeeding was $82.5 \%$ and $17.5 \%$, respectively at enrollment. However, by the end of the $24^{\text {th }}$ week, only $23 \%$ were exclusively breastfeeding their infants, whilst $77 \%$ were practicing non-exclusive breastfeeding. 
Table 1 Anthropometric and body composition changes between EBF and NEBF mothers over 24 weeks

\begin{tabular}{|c|c|c|c|c|c|c|}
\hline Parameter & $\begin{array}{l}\text { Breastfeeding } \\
\text { type }\end{array}$ & $\begin{array}{l}0 \text { weeks } \\
\left(n=171^{\mathrm{E}}, 42^{N}\right)\end{array}$ & $\begin{array}{l}6 \text { weeks } \\
\left(n=161^{E}, 52^{N}\right)\end{array}$ & $\begin{array}{l}14 \text { weeks } \\
\left(n=97^{E}, 116^{N}\right)\end{array}$ & $\begin{array}{l}24 \text { weeks } \\
\left(n=49^{E}, 164^{N}\right)\end{array}$ & $\begin{array}{c}\text { P-value } \\
\text { over time } \\
\text { (6months) }\end{array}$ \\
\hline \multirow[t]{2}{*}{ Weight (kg) } & EBF & $69.46 \pm 10.02$ & $67.93 \pm 10.43$ & $69.50 \pm 10.74$ & $66.93 \pm 10.11$ & Ns \\
\hline & NEBF & $68.88 \pm 11.17$ & $68.54 \pm 10.67$ & $69.95 \pm 10.79$ & $68.32 \pm 10.51$ & Ns \\
\hline \multirow[t]{2}{*}{ Height (m) } & EBF & $1.59 \pm .06$ & $1.59 \pm 0.06$ & $1.59 \pm 0.06$ & $1.59 \pm 0.06$ & Ns \\
\hline & NEBF & $1.59 \pm 0.06$ & $1.59 \pm 0.06$ & $1.59 \pm 0.06$ & $1.59 \pm 0.06$ & Ns \\
\hline \multirow[t]{2}{*}{ BMI $\left(\mathrm{kg} / \mathrm{m}^{2}\right)$} & EBF & $27.32 \pm 3.72$ & $26.67 \pm 3.35$ & $27.45 \pm 3.53$ & $26.33 \pm 3.35$ & Ns \\
\hline & NEBF & $27.00 \pm 3.85$ & $27.06 \pm 3.85$ & $27.33 \pm 3.45$ & $26.82 \pm 3.41$ & Ns \\
\hline \multirow{2}{*}{$\begin{array}{l}\text { Arm } \\
\text { circumference } \\
\text { (cm) }\end{array}$} & EBF & $30.82 \pm 3.53$ & $30.35 \pm 3.86$ & $30.80 \pm 4.19$ & $29.60 \pm 3.77$ & ${ }^{*} 0.025$ \\
\hline & NEBF & $30.42 \pm 3.95$ & $30.36 \pm 4.28$ & $30.48 \pm 4.04$ & $29.55 \pm 4.06$ & Ns \\
\hline \multirow[t]{2}{*}{$\Sigma \mathrm{SFT}(\mathrm{mm})$} & EBF & $41.71 \pm 13.78$ & $42.43 \pm 12.86$ & $45.83 \pm 15.05$ & $44.66 \pm 13.47$ & Ns \\
\hline & NEBF & $44.40 \pm 15.46$ & $45.81 \pm 15.66$ & $47.85 \pm 15.35$ & $48.06 \pm 15.80$ & Ns \\
\hline \multirow[t]{2}{*}{ TBF (\%) } & EBF & $25.00 \pm 4.70$ & $25.36 \pm 4.31$ & $26.36 \pm 4.64$ & $26.12 \pm 4.18$ & ${ }^{*} 0.041$ \\
\hline & NEBF & $25.71 \pm 5.46$ & $26.26 \pm 5.07$ & $26.99 \pm 4.65$ & $27.01 \pm 4.79$ & ns \\
\hline \multirow[t]{2}{*}{ TBF (kg) } & EBF & $17.68 \pm 5.29$ & $17.53 \pm 5.10$ & $18.67 \pm 5.71$ & $17.74 \pm 4.99$ & ns \\
\hline & NEBF & $18.04 \pm 6.03$ & $18.51 \pm 6.06$ & $19.19 \pm 5.53$ & $18.78 \pm 5.54$ & ns \\
\hline \multirow[t]{2}{*}{ LBM (kg) } & EBF & $51.78 \pm 5.89$ & $50.40 \pm 6.21$ & $50.82 \pm 5.94$ & $49.19 \pm 6.06$ & ${ }^{*} 0.031$ \\
\hline & NEBF & $50.49 \pm 5.69$ & $50.37 \pm 5.98$ & $50.75 \pm 6.29$ & $49.54 \pm 6.03$ & ns \\
\hline
\end{tabular}

${ }^{* \star}$ Values in the same row are significantly different over time in each group, ns= Values in the same row are not significantly different over time in each group EBF Exclusive breast feeding, NEBF Non exclusive breast feeding, $\Sigma$ SFT $=$ Sum of skinfold thickness BMI (Body mass index), at different weeks, $\quad n={ }^{N}$ is the number of NEBF infants at different weeks

$n={ }^{E}$ is the number of EBF infants

The anthropometric and body composition characteristics of the mothers practicing exclusive (EBF) and non-exclusive breastfeeding (NEBF) as presented on Table 1 shows that baseline measurements were similar to the values obtained at the end of the study period $(P>0.05)$. However, arm circumference, percent body fat and lean body mass differed significantly over the period $(P<0.05)$. In the case of the NEBF group, no significant difference was observed in the anthropometric and body composition parameters $(P>0.05)$. During the first 6 weeks, there was a slight decrease in weight in both groups with the EBF mothers losing $1.53 \mathrm{~kg}$, while their NEBF counterparts lost $0.33 \mathrm{~kg}$. There was however gain in weight between the $6^{\text {th }}$ and $14^{\text {th }}$ week for both EBF $(0.79 \mathrm{~kg} /$ month $)$ and NEBF $(0.71 \mathrm{~kg} / \mathrm{month})$. After the $14^{\text {th }}$ week, a slight decline occurred in both groups with EBF and NEBF losing 1.03 and $0.65 \mathrm{~kg} / \mathrm{month}$, respectively. Weight gain and weight loss observed at the different times were not significantly different $(P>0.05)$. The mean BMI of mothers in both groups was greater than $25 \mathrm{~kg} / \mathrm{m}^{2}$ at the beginning and end of the study. The mothers were in the overweight category using WHO (1997) BMI classification.

Total body fat $(\mathrm{kg})$ followed a similar trend with mothers practicing exclusive breastfeeding gaining 
average body fat of $0.57 \mathrm{~kg} / \mathrm{month}$ and their NEBF counterparts had a gain of $0.34 \mathrm{~kg} /$ month. After the $14^{\text {th }}$ week, body fat loss was 0.37 and $0.16 \mathrm{~kg} / \mathrm{month}$ for EBF and NEBF mothers. Lean body mass (LBM) over the period was higher in mothers practicing EBF $(0.43 \mathrm{~kg} / \mathrm{month})$ than in their NEBF counterparts (0.16kg/month) $(P>0.05)$.

\section{DISCUSSION}

The study revealed that irrespective of the breastfeeding pattern, anthropometry and body composition did not change significantly. There was however a decrease in the weight of the mothers practicing exclusive and non-exclusive breastfeeding during the first 6 weeks after delivery. This decrease is expected because the postpartum period is associated with weight loss coupled with mobilisation of body water as well as protein and energy needed for milk production (Sarduski et al. 1988; Potter et al., 1991; Motil et al., 1998). The weight gain between 6 and 14 weeks is not surprising. This is because among the "igbos" of Nigeria from which the subjects of this study was drawn, it is a general belief that lactating mothers are supposed to gain weight due to the better feeding expected and the influence of 'doula'. The 'doulas' according to Raphael (1974) are traditionally accepted helpers or experienced mothers who assist new mothers in breastfeeding and new born care. This role is played by mothers/mothers-inlaw, aunties or any other female relative. The idea is to help ease off chores from the mother so that she can rest and breastfeed the child very well. Thus, weight gain is an expectation during this period among the "igbo" tribe in Nigeria. The fact that the study was conducted in an urban setting could also mean that mothers in both groups had access to variety of foods. This could invariably have led to the weight gain that occurred during the first three months of lactation, which also coincides with the "omugwo" (postpartum care) period as it is so called.

Butte and Hopkinson (1998) reported that studies carried out on weight changes during lactation are controversial. In a WHO multicentre Growth Reference Study (MCRS), it was observed that Ghanaian mothers lost little or gained weight during the postpartum period. It was thus reported in that study that culturally defined mother-care practices probably played a role in weight change patterns among Ghanaian lactating women (Onyango et al., 2011). Similarly, a study on a group of Mexicans reported that lactating mothers did not lose weight throughout the first trimester postpartum (i.e. first 3 months of lactation). Cumulative weight gain was $3.8 \mathrm{~kg}$ at the end of three moths in their study.

The cumulative weight loss from delivery to the 24th week in both groups was small; 2.52 and $0.24 \mathrm{~kg}$ in EBF and NEBF mothers, respectively. Okechukwu et al. (2009) reported cumulative weight loss of $4.13 \mathrm{Vs}$ $1.06 \mathrm{~kg}$ between EBF and NEBF mothers, respectively. These are similar to values observed in this study. Hatsu et al (2008) noted that exclusive breastfeeding promotes greater weight loss than mixed feeding, despite the fact that exclusive breastfeeding mothers consume more calories than mothers practicing mixed feeding.

The average BMI in this study indicated that mothers in both groups were overweight $(B M I \geq 25 \mathrm{~kg} / \mathrm{m} 2)$. However, there was a loss in BMI at the end of the study in both groups. This loss was insignificant indicating that weight loss among women who are well nourished may be unnoticeable during lactation because of the adequate energy stores accumulated prior to lactation.

Body fat gain was 0.44 and $0.31 \mathrm{~kg} / \mathrm{month}$ in EBF and NEBF mothers, respectively in the first trimester of lactation. The possibility of increased dietary intake and reduced physical activity levels in subjects in this study cannot be ruled out because of the postpartum care (omugwo) given at this period.

CONCLUSION: This study has shown that irrespective of the breastfeeding pattern, body composition characteristics of the mothers remained normal despite the relatively small weight and fat loss which occurred at the later period of breastfeeding.

Limitation of study: Caution should be exercised in interpreting results in this study due to lack of data on weight gain during pregnancy and pre-pregnancy weight.

\section{ACKNOWLEDGEMENT:}

This research was supported by a grant from Academic Staff Union of Universities (ASUU) and the Federal Government of Nigeria (FGN) in collaboration with Federal Scholarship Board, Abuja (REF: FSBA/FGSS/PG/09/029).

\section{REFERENCES}

Barbosa, L., Butte, N.F., VIllalpando, S., Wong, W.W. \& Smith, E.O. (1997). Maternal balance and lactation performance of Mesoameridians as a function of BMI. Am. J. Clin. Nutr., 66,575-583 
Butte, N.F. \& Hopkinson, J.M. (1998) Body composition changes during lactation are highly variable among women. J. Nutr., 128(2):3815-3855.

Chou, T., Chan, G.M., \& Moyer, L. (1999) Postpartum body composition changes in lactating and non lactating primiparas. Nutr., 15, 481-484.

Deurenberg, P. (1992) The assessment of body composition: uses and mis-uses. Annual Report, Nestle Foundation, Lusanne, Switzerland. pp. 35-72

Dewey, K.G, Heinig, M.J. \& Nommsen, L.A. (1993) Maternal weight loss pattern during prolonged lactation. Am. J. Clin. Nutr., 58,162-166.

Dugdale, A.E. \& Eaton-Evans, J. (1989) The effect of lactation and other factors on postpartum changes in body weight and triceps skin fold thickness. Br. J. Nutr., 61,149-153.

Durnin, J.V.G.A. \& Womersley, J. (1974) Body fat assessed from body density and it's estimation from skin-fold thickness: measurement on 481 men and women from 16-72 years. Br. J. Nutr., 31,77-97.

Hatsu, I.C., McDwgald, D.M. \& Anderson, A.K. (2008) Effect of infant feeding on maternal body composition. Inter. Breastfeeding Journal, 3:18-25

Lunn, P.G. (2004) Breast feeding practices and other metabolic loads affecting human reproduction. In: Variability in Human fertility, Rosetta, L. and C.G.N. Mascie-Taylor (eds). Cambridge University Press, United Kingdom.

Lunn, P.G. (1996) Breast-feeding practicesand other metabolic loads affecting human reproduction. In: Variability in Human Fertility. Rosetta, L. and MascieTaylor, C.G.N (eds) Cambridge University Press. pp. 195-216

Motil, K.J., Sheng H.P., Kertz B.L., Montandon, C.M. \& Ellis, K.J. (1998) Lean body mass of well nourished women is preserved during lactation. Am. J. Clin. Nutr., 67, 292-300.

Naanyu, V. (2010) Young mothers, first time parenthood and exclusive breast feeding in Kenya. Afr. J. Reprod. Hith., 12(3):126-137.

NDHS (2008) Nigeria Demographic and Health SurveyFederal Office of Statistics Lagos, Nigeria. ORC Macro,Calverton, Maryland, USA.

NDHS (2003) Nigeria Demographic and Health SurveyFederal Office of Statistics Lagos, Nigeria. ORC Macro,Calverton, Maryland, USA. pp151-154.
Nwankwo, B.O. \& Brieger, W.R. (2002) Exclusive breast feeding is undermined by the use of other liquids in rural south western Nigeria. J. Trop. Paediatr., 48(2)109-112.

Onyango AW,Nommsen RL, Siyam A, de Onis M, Garza C, Lartey A, Baeny A, Bhandari N,Dewey, KG, Araugo CL, Mohammed J \& den Broeck, J.V. (2011) Postpartum weight change patterns in the WHO Growth Reference Study. 7(3): 228-240.

Okechukwu, A.A., Okpe, EC., Okolo, A.A. (2009) Exclusive breastfeeding and post natal changes in maternal antropomerty. Nig. J. Clin. Practice. 12(4):383-388

Prentice, A., Paul, A., Prentice, A., Black, A., Cole, T \& Whitehead, R. (1986) Cross-cultural differences in lactational performance. New York: Plenum Press.

Potter, S., Hannum, S., McFarlin, B., Essex-Sorlie, D., Campbell, E. and Trupin, S. (1991) Does infant feeding method influence maternal postpartum weight loss? J. Ame. Med. Asso., 91:441-446.

Raphael D. (1973) The tender gift: Breastfeeding. Englewood Cliffs, NJ. Prentice-Hall.

Sarduski, K., Kabur, N., Wager, J. \& Forsum, E. (1988) Energy metabolism, body composition, and milk production in healthy Swedish women during lactation. Am. J. Clin. Nutr., 48, 44-49.

Valleggia, C.R. \& Ellison, P.T. (2003) Impact of breastfeeding on anthropometric changes in periurban Toba women (Argentina). Am. J. Hum. Biol., 15:717-724.

Van-Raaij, J.M.A., Schonk, C.M., Vermaat-Miederna, S.H., Peak, M.C.M. \& Hautvast, G.A.J. (1991) Energy cost of lactation and energy balances in well nourished Dutch lactating women: reappraisal of the extra energy requirements of Lactation. Am. J. Clin. Nutr., 53,612-619.

Vinoy, S., Rosetta, L. \& Mascie-Taylor, C.G.N. (2000) Repeated measurement of energy intake, energy expenditure and energy balance in lactating Bangladesh mothers. Euro.J. Clin. Nutr., 54,579-585.

WHO (1997) Obesity: Preventing and managing the global epidemic of obesity. Report of the World Health organization Consultation on obesity. WHO. Geneva 